\title{
Characterization of subcellular localization of duck enteritis virus UL5 I protein
}

\author{
Chanjuan Shen $^{\dagger 1}$, Yufei Guo ${ }^{\dagger 1}$, Anchun Cheng* ${ }^{* 1,2}$, Mingshu Wang ${ }^{\dagger 1,2}$, \\ Yi Zhou' ${ }^{1}$, Dan Lin ${ }^{1}$, Hongyi Xin ${ }^{1}$ and Na Zhang ${ }^{1}$
}

Address: ${ }^{1}$ Avian Diseases Research Center, College of Veterinary Medicine of Sichuan Agricultural University, Ya'an, Sichuan, 625014, PR China and ${ }^{2}$ Key Laboratory of Animal Diseases and Human Health of Sichuan Province, Ya'an, Sichuan, 625014, PR China

Email: Chanjuan Shen - vorber@163.com; Yufei Guo - gyf02@163.com; Anchun Cheng* - chenganchun@vip.163.com; Mingshu Wang - mshwang@163.com; Yi Zhou - cchng02@163.com; Dan Lin - lindan0107@163.com; Hongyi Xin - hongyi_xin@163.com; Na Zhang - nana821024@sohu.com

* Corresponding author †Equal contributors

Published: 3 July 2009

Virology Journal 2009, 6:92 doi:10.1186/1743-422X-6-92

This article is available from: http://www.virologyj.com/content/6/1/92

(C) 2009 Shen et al; licensee BioMed Central Ltd.

This is an Open Access article distributed under the terms of the Creative Commons Attribution License (http://creativecommons.org/licenses/by/2.0), which permits unrestricted use, distribution, and reproduction in any medium, provided the original work is properly cited.
Received: 13 May 2009

Accepted: 3 July 2009

\begin{abstract}
Background: Knowledge of the subcellular localization of a protein can provide useful insights about its function. While the subcellular localization of many alphaherpesvirus UL5I proteins has been well characterized, little is known about where duck enteritis virus (DEV) UL5I protein (pUL5I) is targeted to. Thus, in this study, we investigated the subcellular localization and distribution of DEV pUL5 I by computer aided analysis, as well as indirect immunofluorescence (IIF) and transmission immunoelectron microscopy (TIEM) approaches in DEV-infected cells.

Results: The DEV UL5I gene product was identified as an approximate $34 \mathrm{kDa}$ protein in DEVinfected cells analyzed by western blotting. Computer aided analysis suggested that DEV pUL5I is not targeted to the mitochondrial, extra-cellular or nucleus, but be targeted to the cytoplasmic in host cells, more specifically, palmitoylation of the pUL5I through the $\mathrm{N}$-terminal cysteine at position 9 makes membrane association and Golgi localization possible. Using IIF analysis, we found that DEV pUL5I was first detected in a juxtanuclear region of DEV-infected cells at $9 \mathrm{~h}$ postinfection (p.i.), and then was detected widely distributed in the cytoplasm and especially was stronger in the juxtanuclear region from 12 to $60 \mathrm{~h}$ p.i. TIEM analysis revealed that DEV pUL5 I was mainly associated with cytoplasmic virions and also with some membranous structure near the PUL5I-specific immuno-labeling intracellular virion in the cytoplasmic vesicles; moreover, the pUL5I efficiently accumulated in the Golgi apparatus at first, and then was sent to the plasma membrane from the Golgi by some unknown mechanism.
\end{abstract}

Conclusion: In this work, we described the basic characteristics of pUL5I subcellular localization and distribution for the first time. From these results, we concluded that palmitoylation at the $\mathrm{N}$ terminal cysteine, which is conserved in all alphaherpesvirus UL5I homologs, is required for its membrane association and Golgi localization, and the PUL5I mainly localized to the juxtanuclear region of DEV-infected cells, as well seemed to be incorporated into mature virions as a component of the tegument. The research will provide useful clues for DEV pUL5I functional analysis, and will be usefull for further understanding the localization properties of alphaherpesvirus UL5I homologs. 


\section{Background}

Duck enteritis virus (DEV) is a member of the subfamily Alphaherpesvirinae, and an important pathogen of waterfowl (ducks, geese, and swans), causing an acute contagious viral disease that result in substantial economic losses [1-3]. The genome of DEV is comprised of an approximate $180 \mathrm{kbp}$ of linear and double-stranded DNA molecule, and its genomic structure is similar to that of other alphaherpesviruses [4,5]. In 2006, the DEV UL51 gene was isolated and identified from DEV CHv strain in our laboratory $[6,7]$. It was reported that UL51 gene of the alphaherpesviruses, which encodes a phosphorylated and palmitoylated tegument protein $[8,9]$, and was high conserved in the alphaherpesvirus family [10]. Recent research has shown that the product of the herpes simplex virus (HSV-1) UL51 gene is a membrane associated protein, eventually incorporated into virions and forming the outer layer of tegument $[9,11]$; moreover, the HSV-1 UL51 protein (pUL51) appears to play multiple roles in viral replication, including egress of virus particles from the perinuclear space and secondary envelopment in the cytoplasm [12].

The infective properties of a virus are determined by the viral proteins that make up its capsid, envelope (tegument), and spikes. Although viruses are acellular organisms, viral proteins are required to reside in various cellular compartments of the host cell to fulfill their functions [13]. Therefore, knowledge of the subcellular localization of viral proteins in a host cell or virus-infected cell is very useful for in-depth studying of their functions and mechanisms as well as designing antiviral drugs. While the intracellular localization of many alphaherpesvirus UL51 proteins, such as HSV-1 [11], bovine herpesvirus 1 (BHV-1) [14], and pseudorabies virus (PrV) [15], has been well characterized, little is known about where DEV pUL51 is targeted to. In the present study, we characterized the DEV pUL51 subcellular localization by computer aided analysis, as well as indirect immunofluorescence (IIF) and transmission immunoelectron microscopy (TIEM) approaches in DEV-infected cells. There would be a strong degree of complementarity between the use of computational tools and experimental methods that can score the likelihood that DEV pUL51 belongs to a given compartment. The research will provide useful clues for DEV pUL51 functional analysis, and will be usefull for further understanding the localization properties of alphaherpesvirus UL51 homologs.

\section{Methods}

\section{Computer aided analysis}

The DEV UL51 gene (GenBank No. DQ072725), with a size of $759 \mathrm{bp}$, encoded a 252 amino acid protein, was identified in our laboratory [6]. Based on predicted amine acid sequence of DEV pUL51, various bioinformatics- aided tools: TargetP 1.1, SignalP 3.0 and TMHMM 2.0 server (from the search engine http://www.cbs.dtu.dk/ services/) [16], PredictNLS server (from the search engine http://www.rostlab.org/services/predictNLS/) [17], CSSPalm 2.0 online server (from the search engine http:// csspalm.biocuckoo.org/online.php) [18], and Golgi predictor (from the search engine http://ccb.imb.uq.edu.au/ golgi/golgi predictor.shtml) [19], were used to analyze the possible localization of the pUL51.

\section{Virus strain and cell}

DEV CHv strain is a high-virulence field strain isolated from china, obtained from Key Laboratory of Animal Disease and Human Health of Sichuan Province [20,21]. Duck embryo fibroblasts (DEF) were cultured in MEM medium (Gibco-BRL) supplemented with $10 \%$ fetal bovine serum (FBS) (Gibco-BRL) at $37^{\circ} \mathrm{C}$. For virus infection, MEM medium supplemented with 2-3\% FBS was used.

\section{Antibody}

A rabbit polyclonal UL51 antiserum (obtained from our Laboratory), raised against a recombinant 6-His-UL51 fusion protein expressed in E. coli, was purified using caprylic acid and ammonium sulfate precipitation and High-Q anion-exchange chromatography [22,23]. The purified UL51 antiserum was subsequently used as primary antibody. Besides, a pre-immune rabbit serum was also obtained from our Laboratory and purified as described above. The purified pre-immune serum was used as a negative control.

\section{Western blotting}

DEF grown in the 6-well plates, were either mock-infected or infected with DEV CHv strain at a multiplicity of 5 PFU per cell, and harvested at $24 \mathrm{~h}$ p.i. Cells were lysed in SDS sample buffer, electrophoretically separated on SDS-polyacrylamide gels (SDS-PAGE) and electrically transferred to polyvinylidene difluoride (PVDF) membranes (Amersham Japan). A nonspecific protein binding was blocked by treating membranes at $4{ }^{\circ} \mathrm{C}$ overnight with TBST $(25$ mmol Tris- $\mathrm{HCl}, 150 \mathrm{mmol} \mathrm{NaCl}, \mathrm{pH} 7.4$, and $0.05 \%$ Tween-20) containing 5\% bovine serum albumin (BSA). Then, the membranes were incubated at $37^{\circ} \mathrm{C}$ for $1 \mathrm{~h}$ with a 1:1000 dilution of the purified UL51 antiserum or preimmune serum in TBST containing $0.1 \%$ BSA. After washing 3 times with TBST, the membranes were incubated at $37^{\circ} \mathrm{C}$ for $1 \mathrm{~h}$ with a $1: 10000$ dilution of goat anti-rabbit peroxidase-labeled second antibody (Sino-American Biotechnology Co., Shanghai, China). Washed 3 times with TBST again, the membranes were subsequently treated with an enhanced chemiluminescence (ECL) western blotting detection system (Amersham) and exposed to Hyperfilm-ECL (Amersham). 


\section{IIF}

DEF, grown on coverslips in the 6-well plates, were either mock-infected or infected as described above. At different times $(3,6,9,12,24,36,48$ and $60 \mathrm{~h}$ p.i.), the cells were fixed with $4 \%$ paraformaldehyde for $20 \mathrm{~min}$ at $4{ }^{\circ} \mathrm{C}$ and permeabilized with $0.1 \%$ Triton $\mathrm{X}-100$ for $20 \mathrm{~min}$ at room temperature. The cells were then washed once with PBS and blocked for $1 \mathrm{~h}$ in PBS containing $10 \%$ BSA at $37^{\circ} \mathrm{C}$. They were then incubated with a 1:100 dilution of the purified UL51 antiserum or pre-immune serum at $4{ }^{\circ} \mathrm{C}$ overnight, washed 3 times for $10 \mathrm{~min}$ in PBS, and then treated with FITC conjugated goat anti-rabbit IgG (SinoAmerican Biotechnology Co.) for 45 minutes at $37^{\circ} \mathrm{C}$. As described by Miller [24], the cell nuclei were visualized by 4',6-diamidino-2-phenylindole (DAPI) counter-staining (5 $\mu \mathrm{g} / \mathrm{ml}$, Beyotime Institute of Biotechnology, Shanghai, China). Fluorescent images were examined under the BioRad MRC 1024 imaging system.

\section{TIEM}

DEF were grown in the 6-well plates and were either mock-infected or infected as described above. At different times $(3,6,9,12,24,36,48$ and 60 h p.i.), the cells were fixed with modified PLP fixative (10 mM NaIO4, $75 \mathrm{mM}$ lysine, $37.5 \mathrm{mM}$ phosphate buffer (PB) ( $\mathrm{pH} 7.4), 4 \%$ paraformaldehyde, $0.1 \%$ glutaraldehyde) for $4 \mathrm{~h}$ and then washed with $0.1 \mathrm{M} \mathrm{PB}$ [25]. The cells were then harvested from the 6-well plates by scraping, resuspended in $\mathrm{PB}$, and pelleted by low-speed centrifugation. The cell pellet was washed with $\mathrm{PB}$, dehydrated through a graded series of ethanol, and embedded in LR White resin (London Resin Company) according to the manufacturer's instructions. Ultrathin sections were collected onto Formvar-coated nickel grids. The sections were incubated with $20 \%$ normal goat serum in PBS containing 1\% BSA for $1 \mathrm{~h}$ at room temperature, washed five times in PBS, and incubated with the purified UL51 antiserum or pre-immune serum adequately diluted in PBS-1\% BSA for $2 \mathrm{~h}$. After five washes in PBS, the sections were incubated for $1 \mathrm{~h}$ with the secondary antibody goat anti-rabbit immunoglobulin conjugated with 10-nm-diameter gold particles (British BioCell International) and then washed five times in PBS and twice in double-distilled water. The sections were double stained with $4 \%$ uranyl acetate for $30 \mathrm{~min}$ followed by Reynold's lead citrate solution for 5 min [11]. Carbon-coated sections were examined with a Hitachi H600 transmission electron microscope at $75 \mathrm{kV}$.

\section{Results}

\section{Subcellular localization prediction of DEV pUL5 I}

The DEV pUL51 contains no potential mitochondrial targeting peptide, signal peptides, transmembrane helices and nuclear localization signal (NLS). However, it possesses one potential palmitoylation site at the position 9 amine acid (cysteine) near the N-terminal of the pUL51 with a high score (4.217). Moreover, the pUL51 is predicted as a Golgi type II membrane protein (Golgi localised transmembrane protein) with index values (20.662) greater than the threshold (20.005).

\section{Reactivity and specificity of the UL5 I antiserum}

The purified UL51 antiserum and pre-immune serum was examined by SDS-PAGE (Fig 1A, lanes 1 and 2). To examine the reactivity and specificity of the UL51 antiserum, SDS-PAGE and western blotting was performed (Fig 1B, lanes 1 to 6 ). The results of western blotting showed that the UL51 antiserum reacted strongly with an approximate $34 \mathrm{kDa}$ protein in lysates of DEV-infected cells (Fig 1B, lane 5). This band was not detected in mock-infected cells (Fig 1B, lane 4), and the pre-immune serum did not recognize any proteins in lysates of DEV-infected cells (Fig $1 \mathrm{~B}$, lane 6). These results indicated that the UL51 antiserum specifically detected the primary translation product of the UL51 gene; therefore, we used this UL51 antiserum for further experiments to study the locations of the DEV pUL51.

\section{Intracellular localization and distribution of DEV pUL5 I in DEV-infected cells}

A detailed analysis of the intracellular localization of DEV pUL51 was investigated using the purified UL51 antiserum or pre-immune serum by IIF staining of mock- and
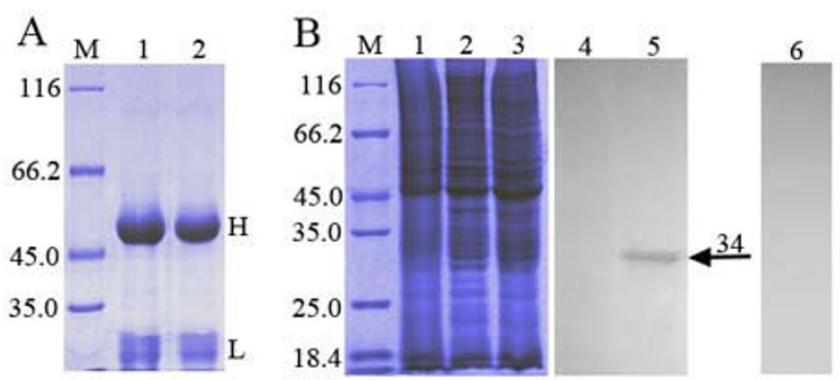

\section{Figure I}

(A) SDS-PAGE analysis of the purified UL5 I antiserum and pre-immune serum. The purified IgG proteins of UL5I antiserum and pre-immune serum were respectively examined by SDS-PAGE (lanes I and 2). Molecular mass markers (in $\mathrm{kDa}$ ) are shown to the left (lane $\mathrm{M}$ ). $\mathrm{H}$ and $\mathrm{L}$ respectively indicate the position of heavy and light chains of the IgG proteins. (B) Reactivity and specificity of the purified UL5 I antiserum analyzed by western blotting. DEF were mock-infected (lanes I and 4) or infected with DEV CHv strain (lanes 2, 3, 5 and 6) and harvested at 24 h p.i. The pUL5 I was separated by SDS-PAGE (lanes I to 3) and analyzed by western blotting using the UL5I antiserum (lanes 4 and 5) or the pre-immune serum (lane 6). Molecular mass markers (in $\mathrm{kDa}$ ) are shown to the left (lane $\mathrm{M}$ ). The arrowhead indicates the position of the PUL5I (about 34 $\mathrm{kDa})$. 
DEV-infected cells. As shown in Fig 2, a faint pUL51-specific fluorescence was first detected in the cytoplasm of DEV-infected cells at $9 \mathrm{~h}$ p.i. (Fig 2C), and then a strong fluorescence was observed mainly in the juxtanuclear region at $12 \mathrm{~h}$ p.i. (Fig 2D). After that, the pUL51-specific fluorescence in the juxtanuclear region was dense and localized on wide areas of the cytoplasm. At $36 \mathrm{~h}$ p.i. (Fig 2E), the pUL51-specific fluorescence was found widely distributed in the cytoplasm and especially was stronger in the juxtanuclear region; meanwhile, the nucleus of some DEV-infected cells also contained little fluorescence granular. Following by a series of morphological changes, the cytoplasm disintegration and nuclear fragmentation in DEV-infected cells, the intensity of the reaction increased at 48 and $60 \mathrm{~h}$ p.i. (Fig 2F), while the pUL51specific fluorescence was mainly detected in the cytoplasm of infected cells and that one localized in the nuclear was faint. No pUL51-specific fluorescence could be detected in mock-infected cells reacted with the UL51 antiserum (Fig 2A) and in DEV-infected cells reacted with the pre-immune serum (Fig 2B).

\section{Subcellular localization and distribution of DEV pUL5 I in DEV-infected cells}

To identify the precise localization of DEV pUL51 in DEVinfected cells, TIEM was carried out. Immunoelectron microscopy showed that at $6 \mathrm{~h}$ p.i., only a little pUL51specific immuno-labeling was first observed in the cytoplasm of DEV-infected cells (data not shown). At $12 \mathrm{~h}$ p.i., intense pUL51-specific immuno-labeling was detected in the juxtanuclear region (Fig. 3B), probably associated with Golgi apparatus. After that, ultrastructural changes of DEV-infected cells were especially remarkable, an increasing number of virus particles were accumulated in the cytoplasm with expansion of endoplasmic reticulum and formation of specialized vesicles. Starting from 24 h p.i., some immuno-labeling was found being associated with cytoplasmic virions and also with some membranous structure that was observed near the pUL51-specific immuno-labeling cytoplasmic virions in the cytoplasmic vesicles (Fig. 3C), and thereafter increasingly until 48 p.i. (Fig. 3D). At later times (60 h p.i.), the positive labeling was mainly localized in the cytoplasm and especially was scattered near the plasma membrane of DEV-infected cell (data not shown). No pUL51-specific immuno-labeling was seen in the DEV-infected cells reacted with the preimmune serum (Fig. 3A) and in the mock-infected cells reacted with the UL51 antiserum (data not shown).

\section{Discussion}

Proteins must be localized in the same sub-cellular compartment to co-operate towards a common biological function. The native subcellular localization of a protein is important for the understanding of its function [17]. However, due to the difficulties in the experimental deter- mination of protein's cellular localization, the methods of theoretical prediction on the known sequence are becoming more important [26]. Computational tools provide fast and accurate localization predictions for any organism [17]. Generally, proteins are sorted into one of four localization classes: extra-cellular, cytoplasmic, nuclear and mitochondrial [27]. Our results of computer aided analysis revealed that the DEV pUL51 is not targeted to the mitochondrial, extra-cellular or nucleus, suggesting that it is targeted to the cytoplasmic in host cells, similar to the homologous proteins of HSV-1, BHV-1, and PrV $[11,14,15]$.

Protein palmitoylation is one of the most ubiquitous post-translational modifications, reversibly attaching a 16-carbon saturated fatty acid as lipid palmitate to cysteine residues in protein substrates through thioester linkage. Also, palmitoylation is thought to be important in regulating intracellular trafficking, sorting, subcellular localization, protein-protein interactions, and functional activities of the proteins $[28,29]$. It has been reported that a number of viruses encode palmitoylated proteins, which play important roles in the process of virus replication [11,30-36]. In additional, previous reports have shown that palmitoylation of the N-terminal cysteine at position 9 (Cys-9) of the HSV-1 pUL51 is necessary for targeting to the Golgi apparatus [11]. From our results, one palmitoylation site is predicted at 9th cysteine of the DEV pUL51, suggesting that the pUL51 is also palmitoylation, and shares higher levels of homology with that of HSV-1. We thus inferred that palmitoylation at the N-terminal cysteine, which is conserved in all alphaherpesvirus UL51 homologs [15], is required for its membrane association and Golgi localization, although we cannot rule out the possibility that the pUL51 has another signal for its subcellular localization.

As we known, the Golgi Apparatus is an organelle central to the biosynthetic pathway of eukaryotic cells as it plays a principal role in the post-translational modification of newly synthesized proteins and in the sorting, packaging and distribution of these proteins to various destinations. To date, all the endogenous single membrane spanning proteins resident within the Golgi apparatus are Type II (cytoplasmic N-terminus/lumenal C-terminus) [19]. Our results of computer aided analysis indicated that the DEV pUL51 is also a Type II membrane protein, which contains a cytoplasmic N-terminus. Taking the above results, it is possible that the DEV pUL51 residents in the Golgi apparatus.

Furthermore, experimentally unravelling the native compartment of a protein also constitutes one step on the long way to determining its function [17]. Experimental determination of a protein subcellular localization is mainly 

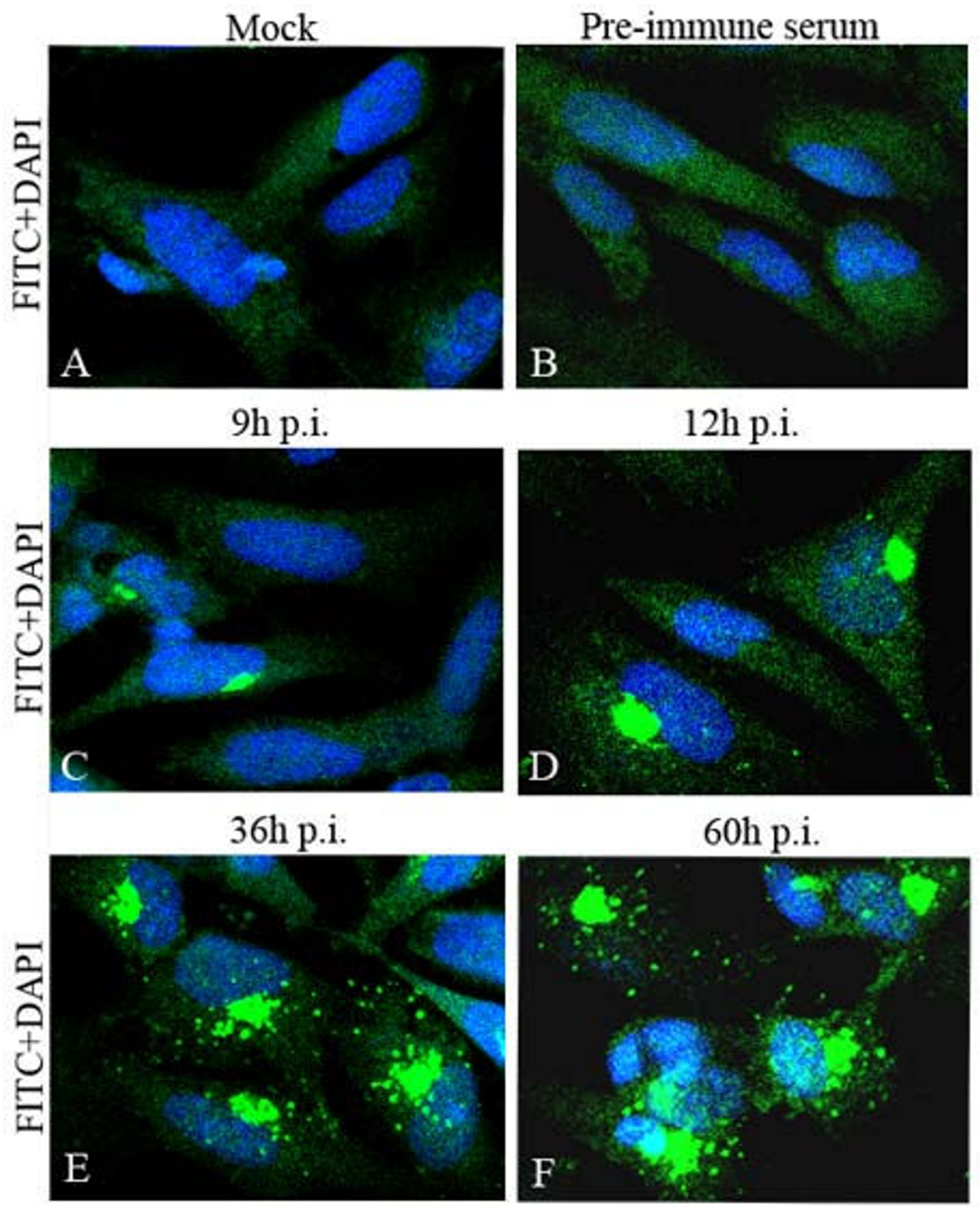

\section{Figure 2}

Intracellular location and distribution of DEV pUL5 I analyzed by IIF. Mock-infected (A) and DEV-infected (B to F) DEF were fixed as described in Materials and Methods. The samples were stained with the UL5I antiserum (A, C to F) or preimmune serum (B), and reacted with anti-rabbit IgG-conjugated FITC, and then counter-stained with DAPI (blue is representative the cell nuclei). The merged fluorescence microscopy images of DEF are shown in panels $A$ to $F$ with high magnification $(600 x)$. 

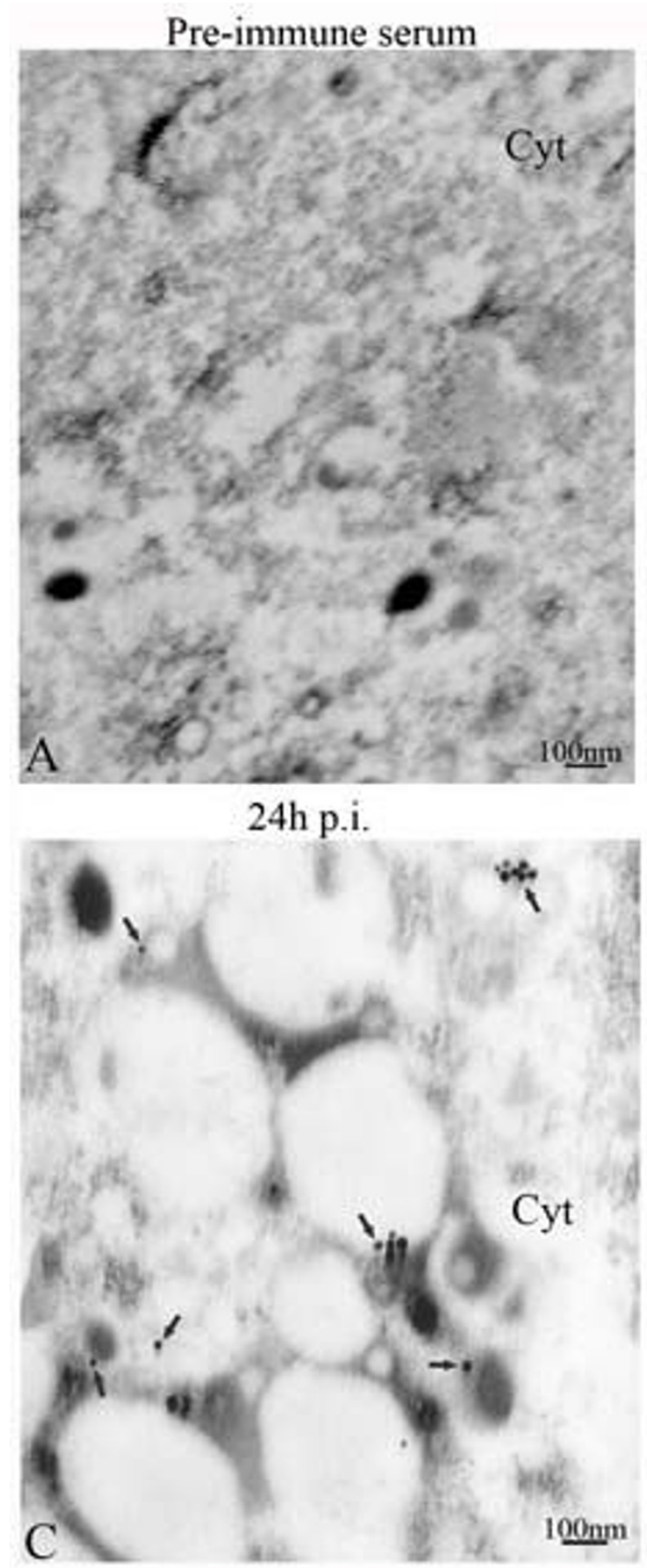

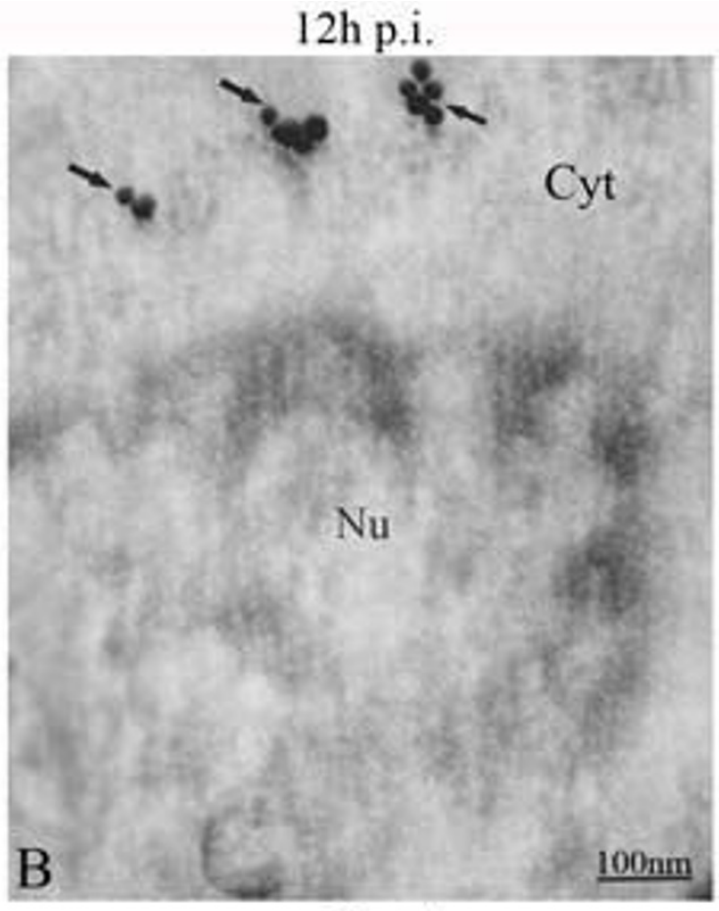

$48 \mathrm{~h}$ p.i.

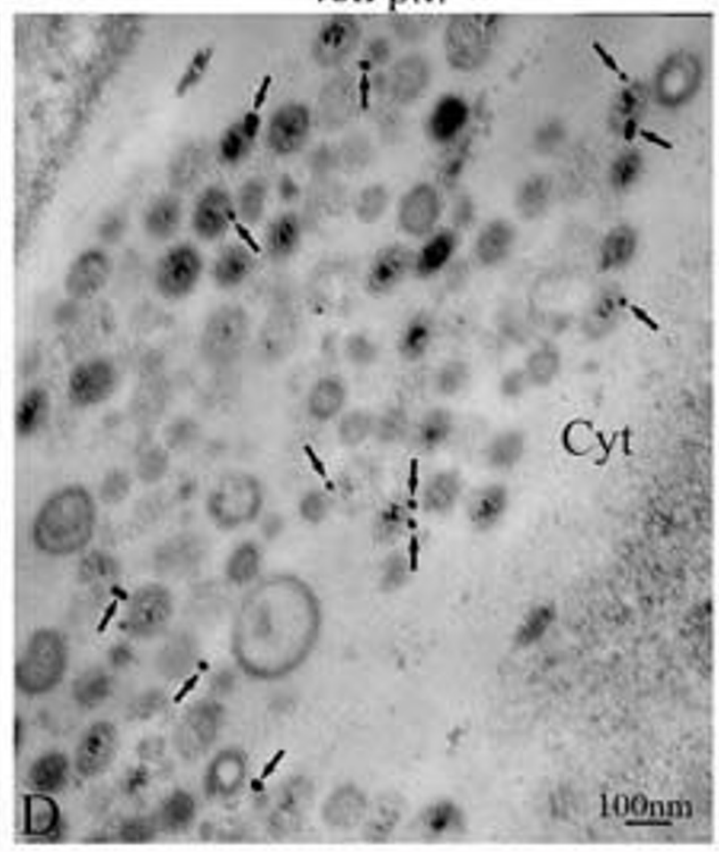

\section{Figure 3}

Subcellular location and distribution of DEV pUL5I analyzed by TIEM. Thin sections were prepared as described in Materials and Methods and incubated with the UL5I antiserum (B to D) or pre-immune serum (A) after treatment with $20 \%$ normal goat serum to block nonspecific antibody reactions. Samples were then incubated with anti-rabbit lgG-conjugated I0nm-diameter gold particles. After extensive rinsing, sections were stained with uranyl acetate and lead citrate and examined with a Hitachi $\mathrm{H} 600$ transmission electron microscope at $75 \mathrm{kV}$. No specific immunolabeling was seen in the cells reacted with pre-immune serum (A). Immunolabelling for pUL5I (arrows) was found in the juxtanuclear region (B). Some immunolahelling for pUL5I (arrows) was found being associated with cytoplasmic virions and also with some membranous structure in the cytoplasmic vesicles (C and D). Abbreviations: Cyt, cytoplasm; Nu, nucleus. Bars represent $100 \mathrm{~nm}$. 
accomplished by three approaches: cell fractionation, fluorescence microscopy and electron microscopy. Due to the cell fractionation approach is very sensitive to contaminations, we chose the fluorescence microscopy and electron microscopy approach to investigate the characteristics of pUL51 subcellular localization in this study.

Firstly, the results of IIF analyses revealed DEV pUL51 was found predominantly in the cytoplasm and especially in the juxtanuclear region, where they were detected as speckled or punctuate patterns in DEV-infected cells. These patterns are very similar to HSV-1 [11], BHV-1 [14] and PrV [15] pUL51 in viral infected cells. Moreover, Nozawa et al. reported that HSV-1 pUL51 localized to the juxtanuclear region, but only partially colocalized with the Golgi maker proteins such as the Golgi $58 \mathrm{~K}$ protein and Golgi Matrix Protein (GM130) in HSV-1 infected cells [11]. Thus, combined with the mentioned above, we inferred that DEV pUL51 might remain mainly concentrated in the Golgi apparatus and ensures its incorporation into assembling virions.

Secondly, our TIEM analysis showed that an association of DEV pUL51-specific labeling with cytoplasmic virions and also with some membranous structure observed near the intracellular virion. Previous studies have reported that the HSV-1 pUL51 is eventually incorporated into virions and localized mainly to the inner side of cytoplasmic vesicles and/or the viral envelope in viral infected cells using protease digestion analysis [11]. These abservations suggested that the DEV pUL51 might be associated with viral envelopment in DEV-infected cells, and seemed to be incorporated into mature virions as a component of the tegurneut, similar to the HSV-1 pUL51.

Besides, it is reported that both proteins, HSV-1 UL11 and UL51, seem to contain specific Golgi-targeting signals, suggesting that both proteins might serve similar functions [15]. Recently, Loomis et al. reported that the tegument protein UL11 localizes to both the Golgi apparatus and the plasma membrane in HSV-1-infected cells [37]. Thus, like the HSV-1 UL11 protein, the DEV pUL51 also might efficiently accumulate in the Golgi apparatus at first, and then were sent to the plasma membrane from the Golgi by some unknown mechanism.

\section{Conclusion}

In this study, we described the basic characteristics of pUL51 subcellular localization and distribution for the first time. From these results, we concluded that palmitoylation at the N-terminal cysteine, which is conserved in all alphaherpesvirus UL51 homologs, is required for its membrane association and Golgi localization, and the pUL51 mainly localized to the juxtanuclear region of
DEV-infected cells, as well seemed to be incorporated into mature virions as a component of the tegument, consistent with its HSV-1 homolog UL51. The research will provide useful clues for DEV pUL51 functional analysis, and will be usefull for further understanding the localization properties of alphaherpesvirus UL51 homologs. Further studies will be aimed at constructing of the UL51 gene DEV mutant to study the function of the DEV pUL51.

\section{Competing interests}

The authors declare that they have no competing interests.

\section{Authors' contributions}

CJS, YFG, ACC and MSW carried out most of the experiments and drafted the manuscript. YZ, DL, HYX and NZ helped in experiments and drafted the manuscript. All authors read and approved the final manuscript.

\section{Acknowledgements}

The research were supported by grants from the National Natural Science Foundation of China (No. 3077I598), Changjiang Scholars and Innovative Research Team in University (PCSIRT0848), the New Century Excellent Talents Program in University (NCET-06-0818), the Cultivation Fund of the Key Scientific and Technical Innovation Project, the Ministry of Education of China (No. 706050), the Cultivation Fund of the Key Scientific and Technical Innovation Project, Department of Education of Sichuan Province (No. 07ZZ028), the Sichuan Province Outstanding Youths Fund (07ZQ026-I32) and the Sichuan Province Basic Research Program (07JY029-016/07JY029017).

\section{References}

I. Sandhu TS, Shawky SA: Duck virus enteritis. In Diseases of poultry Edited by: Saif YM, Barnes HJ, Glisson JR. New York: lowa State University Press; 2003:354-363.

2. Brand CJ, Docherty DE: A survey of North American migratory waterfowl for duck plague (duck virus enteritis) virus. J Wild Dis 1984, 20:261-266.

3. Salguero FJ, Sanchez-Cordon PJ, Nunez A, Gomez-Villamandos JC: Histopathological and ultrastructural changes associated with herpesvirus infection in waterfowl. Avian Pathol 2002 , 3 I: I33-I40.

4. Gardner R, Wilkerson J, Johnson JC: Molecular characterization of the DNA of Anatid herpesvirus I. Intervirology 1993, 36:99-I I 2.

5. Lee LF, Wu P, Sui D, Ren D, Jeremy K, Kung HJ, Witter RL: The complete unique long sequence and the overall genomic organization of the GA strain of Marek's disease virus. PNAS 2000, 97:6091-6096.

6. Cheng AC, Wang MS, Wen M, Zhou WG, Guo YF, Jia RY, Xu C, Yuan GP, Liu YC: Construction of duck enteritis virus gene libraries and discovery, cloning and identification of viral nucleocapsid protein gene. High Technol Lett 2006, I 6:948-953.

7. Xie W, Cheng AC, Wang MS, Chang H, Zhu DK, Luo QH, Jia RY, Chen $X Y$ : Expression and characterization of the UL3I protein from Duck enteritis virus. Virol J 2009, 6:19.

8. Daikoku T, Ikenoya K, Yamada H, Goshima F, Nishiyama Y: Identification and characterization of the herpes simplex virus type I UL5 I gene product. J Gen Virol 1998, 79(Pt I 2):3027-303 I.

9. Mukhopadhyay A, Lee GE, Wilson DW: The amino terminus of the herpes simplex virus I protein Vhs mediates membrane association and tegument incorporation. J Virol 2006, 80:10117-10127.

10. Roizman Bernard, Knipe David M: Herpes simplex viruses and their replication. In Fundamental virology Edited by: David M Knipe, Peter M Howley. Philadelphia: Lippincott Williams - Wilkins; 200I:II23-II84. 
I I. Nozawa N, Daikoku T, Koshizuka T, Yamauchi Y, Yoshikawa T, Nishiyama $Y$ : Subcellular localization of herpes simplex virus type I UL5 I protein and role of palmitoylation in Golgi apparatus targeting. J Virol 2003, 77:3204-32I6.

12. Nozawa N, Kawaguchi Y, Tanaka M, Kato A, Kato A, Kimura H, Nishiyama $Y$ : Herpes simplex virus type I UL5 I protein is involved in maturation and egress of virus particles. J Virol 2005, 79:6947-6956.

13. Shen HB, Chou KC: Virus-PLoc: a fusion classifier for predicting the subcellular localization of viral proteins within host and virus-infected cells. Biopolymers 2007, 85:233-240.

14. Hamel F, Boucher H, Simard C: Transcriptional and translational expression kinetics of the bovine herpesvirus I UL5 I homologue gene. Virus Res 2002, 84: I25-134.

15. Klupp BG, Granzow H, Klopfleisch R, Fuchs W, Kopp M, Lenk M, Mettenleiter TC: Functional analysis of the pseudorabies virus UL5 I protein. J Virol 2005, 79:383 I-3840.

16. Emanuelsson $\mathrm{O}$, Brunak S, von Heijne G, Nielsen H: Locating proteins in the cell using TargetP, SignalP and related tools. Nat Protoc 2007, 2:953-97I.

17. Nair R, Rost B: LOC3D: annotate sub-cellular localization for protein structures. Nucleic Acids Res 2003, 3 I:3337-3340.

18. Ren J, Wen L, Gao X, Jin C, Xue Y, Yao X: CSS-Palm 2.0: an updated software for palmitoylation sites prediction. Protein Eng Des Sel 2008, 2 I:639-644.

19. Yuan Z, Teasdale RD: Prediction of Golgi Type II membrane proteins based on their transmembrane domains. Bioinformatics 2002, I 8: I 109-III5.

20. Guo YF, Cheng AC, Wang MS, Zhou Y: Purification of anatid herpesvirus I particles by tangential-flow ultrafiltration and sucrose gradient ultracentrifugation. J Virol Methods 2009 in press.

21. Yuan GP, Cheng AC, Wang MS, Liu F, Han XY, Liao YH, Xu C: Electron microscopic studies of the morphogenesis of duck enteritis virus. Avian Dis 2005, 49:50-55.

22. Perosa F, Carbone R, Ferrone S, Dammacco F: Purification of human immunoglobulins by sequential precipitation with caprylic acid and ammonium sulphate. J Immunol Methods 1990, 128:9-16.

23. McGuire JM, Douglas M, Smith KD: The resolution of the neutral $\mathrm{N}$-linked oligosaccharides of IgG by high pH anion-exchange chromatography. Carbohydr Res 1996, 292:1-9.

24. Miller WJ, Skinner JA, Foss GS, Davies KE: Localization of the fragile $X$ mental retardation 2 (FMR2) protein in mammalian brain. Eur J Neurosci 2000, I 2:38|-384.

25. Nozawa N, Daikoku T, Yamauchi Y, Takakuwa H, Goshima F, Yoshikawa T, Nishiyama Y: Identification and characterization of the UL7 gene product of herpes simplex virus type 2. Virus Genes 2002, 24:257-266.

26. Nakai K: Protein sorting signals and prediction of subcellular localization. Adv Protein Chem 2000, 54:277-344.

27. Nair R, Rost B: Better prediction of sub-cellular localization by combining evolutionary and structural information. Proteins 2003, 53:917-930.

28. Dunphy JT, Linder ME: Signalling functions of protein palmitoylation. Biochim Biophys Acta 1998, 1436:245-26I.

29. Dietrich LE, Ungermann C: On the mechanism of protein palmitoylation. EMBO Rep 2004, 5:1053-1057.

30. Zusinaite E, Tints K, Kiiver K, Spuul P, Karo-Astover L, Merits A Sarand I: Mutations at the palmitoylation site of non-structural protein nsPI of Semliki Forest virus attenuate virus replication and cause accumulation of compensatory mutations. J Gen Virol 2007, 88: 1977-1985.

31. Yu GY, Lee KJ, Gao L, Lai MM: Palmitoylation and polymerization of hepatitis C virus NS4B protein. J Virol 2006, 80:6013-6023.

32. Sugrue RJ, Belshe RB, Hay AJ: Palmitoylation of the influenza A virus M2 protein. Virology 1990, I 79:5I-56.

33. Ochsenbauer-Jambor C, Miller DC, Roberts CR, Rhee SS, Hunter E. Palmitoylation of the Rous sarcoma virus transmembrane glycoprotein is required for protein stability and virus infectivity. J Virol 200 I, 75: I I544- I I554.

34. Hensel J, Hintz M, Karas M, Linder D, Stahl B, Geyer R: Localization of the palmitoylation site in the transmembrane protein pI2E of Friend murine leukaemia virus. Eur J Biochem 1995, 232:373-380.
35. Li M, Yang C, Tong S, Weidmann A, Compans RW: Palmitoylation of the murine leukemia virus envelope protein is critical for lipid raft association and surface expression. J Virol 2002, 76: I | 845-। I852

36. Loomis JS, Bowzard JB, Courtney RJ, Wills JW: Intracellular trafficking of the ULI I tegument protein of herpes simplex virus type I. J Virol 200I, 75:12209-I22I9.

37. Loomis JS, Courtney RJ, Wills JW: Packaging determinants in the ULI I tegument protein of herpes simplex virus type I. J Virol 2006, 80: 10534-1054|.

Publish with Bio Med Central and every scientist can read your work free of charge

"BioMed Central will be the most significant development for disseminating the results of biomedical research in our lifetime. "

Sir Paul Nurse, Cancer Research UK

Your research papers will be:

- available free of charge to the entire biomedical community

- peer reviewed and published immediately upon acceptance

- cited in PubMed and archived on PubMed Central

- yours - you keep the copyright 